\title{
Vozes femininas silenciadas: o jornalismo literário de Svetlana Aleksiévitch como resistência à espiral do silêncio produzida pelo patriarcado
}

\section{Emerson Campos Gonçalves'}

\section{Resumo}

A construção simbólica de gênero é uma das principais estratégias que ajudam a sociedade patriarcal a se perpetuar. Para isso, um sem fim de vozes femininas são silenciadas nos diferentes campos discursivos de representação social (jornalismo, ciência, cinema e outros) frente a relatos que buscam impor uma perspectiva masculina - muitas vezes distorcida - da história. Tomando o pressuposto de que apenas uma reunião de vozes femininas é capaz de quebrar essa espiral do silêncio, realizou-se a análise hermenêutica do livro "A guerra não tem rosto de mulher", de Svetlana Aleksiévitch, marco na representação de discursos femininos sobre a Segunda Guerra (1939-1945). O objetivo foi identificar no jornalismo literário da autora estratégias de resistência à espiral que, sob novos moldes, persiste.

Palavras-chave: Jornalismo Literário. Espiral do Silêncio. Feminismo.

\section{Silenced female voices: Svetlana Aleksevich's literary journalism as resistance to the spiral of silence produced by patriarchy}

\section{Abstract}

The symbolic construction of gender is one of the main strategies that help patriarchal society to perpetuate itself. For this, an endless number of female voices are silenced in the different discursive fields of social representation

1 Doutorando no Programa de Pós-Graduação em Educação na Universidade Federal do Espírito Santo (PPGE/Ufes) com bolsa Capes. Pesquisador no Núcleo de Estudos e Pesquisa em Educação, Filosofia e Linguagens (Nepefil/Ufes). Mestre em Estudos de Linguagens (Posling/Cefet-MG), bacharel em Comunicação Social/Jornalismo (PUC Minas) e licenciado em Letras/Português (Ifes). E-mail: emer.cg@gmail.com

Revista Pauta Geral-Estudos em Jornalismo, Ponta Grossa, vol. 6, n. 2, p. 3-19, Jul/Dez, 2019. 


\section{REVISTA PAUTA GERAL}

\section{ESTUDOS EM JORNALISMO}

10.5212/RevistaPautaGeral.v.6.i2.0001

(journalism, science, cinema, and others) in front of speeches that seek to impose a male - often distorted - perspective on history. Assuming that only a gathering of female voices can break this spiral of silence, it was performed an hermeneutic analysis of Svetlana Aleksievitch's book, "The unwomanly face of war," a landmark in the representation of female discourses on Second World War (1939-1945). The objective was to identify, in the author's literary journalism, strategies of resistance to the spiral that, although under new molds, persist.

Keywords: Literary Journalism. Spiral of Silence. Feminism.

\section{Introdução}

A construção simbólica de gênero é uma das principais estratégias que permitem que as sociedades patriarcais ${ }^{2}$ ainda perpetuem na contemporaneidade. Na prática, isso ocorre a partir da elaboração de representações sociais ditadas predominantemente pela voz masculina, que se empenha em criar adjetivos que naturalizem alguns comportamentos como tipicamente femininos, compondo como destino desejável e/ou inevitável para as mulheres condições de inferioridade ou servidão, como, por exemplo, a famosa tríade "bela, recatada e do lar"3. Essa lógica é responsável não apenas por emudecer um sem fim de vozes femininas, estabelecendo uma verdadeira espiral do silêncio frente o ciclo perverso de violência e dominação do discurso do homem, como também por criar inúmeras narrativas históricas que não passam de simulacros ou sombras distorcidas da realidade, vez que a "versão oficial" dos fatos quase sempre é contada pelo ponto de vista masculino, relegando às mulheres um papel menor ou secundário.

\footnotetext{
2 Patriarcado, de modo geral, se refere a um espaço/conjunto governado pelo homem, chefe da unidade social. Apropriado pelas pensadoras feministas do século XX, o termo passou a ser utilizado para definir o sistema social de dominação masculina sobre as mulheres (ACUÑA, 2019). Ainda que reconhecendo as críticas realizadas dentro das Teorias Feministas ao conceito, apontado por algumas correntes como 'universalista', sua contribuição a partir da relação dual capitalismo/patriarcado tem sido fundamental no estudo das sociedades contemporâneas.

3 A expressão "bela, recatada e do lar" ganhou notoriedade depois da publicação de um perfil na Revista Veja, em 18 de abril de 2016, sobre Marcela Temer, esposa do então vice-presidente Michel Temer. Num contexto de golpe de estado contra a presidenta Dilma Rousseff, a tentativa discursiva do periódico de reservar à mulher um lócus de passividade e inferioridade na trama política trouxe repercussão imediata entre as feministas. Para Silva, Azevedo e Filgueiras (2017, p. 224), com esse enunciado, a Veja trouxe um "um já-dito, cristalizado, acerca da posição-sujeito da mulher, como aquela que não reclama, está sempre sorrindo e nunca bateria de frente com o marido".
}

Revista Pauta Geral-Estudos em Jornalismo, Ponta Grossa, vol. 6, n. 2, p. 3-19, Jul/Dez, 2019. 


\section{REVISTA PAUTA GERAL}

\section{ESTUDOS EM JORNALISMO}

10.5212/RevistaPautaGeral.v.6.i2.0001

É Simone de Beauvoir quem, já nas primeiras páginas de O Segundo Sexo, publicado originalmente em 1949, denuncia essa construção simbólica que persiste como estratégia sob a batuta patriarcal: "Legisladores, sacerdotes, filósofos, escritores e sábios empenharam-se em demonstrar que a condição subordinada da mulher era desejada no céu e proveitosa à terra" (BEAUVOIR, 1970, p. 16, grifo meu). Tomando as características e os desafios das sociedades hodiernas, pode-se incluir com segurança nessa lista - sem qualquer prejuízo à intenção da filósofa francesa - agentes da indústria cultural como produtores fonográficos, diretores de cinema, publicitários e, sobretudo, jornalistas, sendo esses últimos, através dos mass media, responsáveis diretos pela construção da imagem que cada indivíduo projeta no seu íntimo sobre os papeis e expectativas que a sociedade Ihe reserva a depender de sua classe, cor, orientação sexual e gênero.

Considerando o cenário supramencionado, é importante destacar que as possibilidades do jornalismo moderno [e dos jornalistas] se encerram em dois caminhos opostos. O mais fácil deles tem sido adotado ao longo da história brasileira por incontáveis veículos hegemônicos que se apressam em prestar serviços a um sistema de representação social misógino (MÉNDEZ, 2007), fortalecendo as estratégias discursivas responsáveis por criar um campo ideológico que legitima a subordinação das mulheres. Contudo, existe o caminho da resistência na mídia alternativa (WOITOWICZ, 2008, 2012), onde a liberação das vozes femininas - e feministas - passa a ser o principal objetivo de um jornalismo contra-hegemônico, baseado em práticas dialógicas e libertadoras.

O livro A Guerra não tem rosto de mulher, da jornalista bielorrussa Svetlana Aleksiévitch, é uma das obras que ilustram esse jornalismo de resistência que busca garantir que as múltiplas vozes femininas consigam espaço e meio para se propagar. Vencedora do Prêmio Nobel de Literatura em 2015, a autora passou sete anos coletando relatos de centenas de mulheres que lutaram no Exército Vermelho durante a Segunda Guerra Mundial (1939-1945). Com o livro, publicado originalmente em 1985, a jornalista objetivou contar a história silenciada pelos homens que, em suas narrativas de guerra, se esforçaram para destinar papeis de enfermeiras zelosas ou mães e esposas preocupadas às ex-combatentes, eliminando o que chamavam (os homens) de "ninharias de mulher" (ALEKSIÉVITCH, 2016, p. 22).

Ao reunir em uma só obra relatos silenciados por décadas, Aleksiévitch nos traz "um exemplo vivo da experiência coletiva na narrativa" (GONÇALVES; LOUREIRO, 2018, p. 209). A partir de tensionamentos entre tempos distintos de apuração, entrevistas e a Revista Pauta Geral-Estudos em Jornalismo, Ponta Grossa, vol. 6, n. 2, p. 3-19, Jul/Dez, 2019. 


\section{REVISTA PAUTA GERAL}

\section{ESTUDOS EM JORNALISMO}

10.5212/RevistaPautaGeral.v.6.i2.0001

reunião dos relatos no livro, a autora consegue, pelas vias do jornalismo, contribuir para a emancipação de mulheres que viviam presas dentro de uma história fictícia, justificada por argumentos absurdos, como o medo masculino "de que elas não contassem direito a guerra" (ALEKSIÉVITCH, 2016, p. 21).

Tomando o jornalismo literário de Svetlana Aleksiévitch como um marco de resistência e um modelo de produção contra-hegemônica, busca-se neste artigo verificar quais estratégias presentes em $A$ guerra não tem rosto de mulher podem contribuir para a resistência à espiral do silêncio produzida pelo patriarcado que insiste em persistir de diferentes formas na sociedade brasileira. Para isso, buscando facilitar a leitura e o debate proposto, dividiu-se a sequência deste trabalho em três partes principais, a saber: i) partese de uma breve discussão sobre as aproximações e afastamentos que marcaram/marcam a história entre feminismo e jornalismo, contextualizando a formação de uma espiral do silêncio nesse cenário; ii) conceitua-se o jornalismo literário como uma alternativa viável para a produção de discursos contra-hegemônicos na atualidade; e, por fim, iii) realiza-se uma análise hermenêutica da obra de Aleksiévitch, apontando suas principais contribuições para a prática de um jornalismo de resistência.

\section{Espiral do silêncio e feminismo na imprensa brasileira: breves apontamentos}

De forma resumida, a teoria da espiral do silêncio proposta pela pesquisadora alemã Elisabeth Noelle-Neuman aponta que, com medo da solidão social que se propaga em espiral, os indivíduos tendem a buscar abrigo nas opiniões hegemônicas, ainda que em seu íntimo discordem das ideias predominantes na opinião pública e precisem silenciar sua própria voz, o que favorece que o status quo [de machismo, sexismo, misogina] perpetue, tornando mais difíceis as mudanças em tópicos sensíveis ao grupo dominante [no caso, a sociedade patriarcal] (NOELLE-NEUMAN, 1995; PENA, 2018).

A ameaça de isolamento funciona sobretudo em períodos revolucionários e de mudança, quando um valor, um costume, um hábito ou uma constelação de poderes ficam sob ataque na sequência de uma descoberta, de mudanças nas condições de vida, de crises, de mudanças de poder ou de um despertar da consciência. É neste tipo de situações que a espiral do silêncio é desencadeada, quando a ideologia, a agitação e as emoções entram em jogo (ALEXANDRE, 2018, p. 187). 


\section{REVISTA PAUTA GERAL}

\section{ESTUDOS EM JORNALISMO}

10.5212/RevistaPautaGeral.v.6.i2.0001

Trata-se, trocando os termos, de reconhecer que os indivíduos se importam consideravelmente com as opiniões do grupo, a ponto de abrirem mão da própria autonomia discursiva quando a espiral é formada, já que, nas palavras de Noelle-Neuman (1995), "nossa natureza social nos faz temer a separação e o isolamento dos demais, bem como desejar que sejamos queridos por eles" (NOELLE-NEUMAN, 1995, n.p, tradução nossa). Ou seja, para não se tornar uma unidade isolada do conjunto, paradoxalmente se renuncia à própria singularidade e voz.

No processo supracitado, os mass media - enquanto espaço privilegiado para formação da opinião pública - surgem como um aliado fundamental. Isso porque, segundo propõe Noelle-Neuman (1995), cada indivíduo possui a capacidade de perceber o "clima de opinião" em determinado momento histórico, mas para isso depende de uma mediação com os diferentes tópicos e assuntos que servirão de pauta para o grupo. Assim, para conseguir sondar e monitorar esse clima, as pessoas "dependem em grande parte dos media" (ALEXANDRE, 2018, p. 187), ficando totalmente dependentes deles "quando se trata de questões e assuntos com os quais não têm uma relação direta" (ALEXANDRE, 2018, p. 187). E é a partir dessa dependência que a mídia hegemônica molda as perspectivas que predominam nos debates na opinião pública, silenciando [ou abafando] as demais vozes a partir de três mecanismos principais: acumulação [ou exposição constante de um determinado tema na mídia]; consonância [ou trato semelhante às notícias sobre esse determinado tópico]; e ubiquidade [ou presença massiva das mídias em múltiplos espaços/lugares] (PENA, 2018, p.156).

Partindo da teoria proposta por Noelle-Neuman (1995) e tomando os três mecanismos dos quais a mídia se serve, não é tarefa hercúlea compreender a dinâmica de funcionamento que condiciona a formação de uma espiral do silêncio a partir da construção simbólica de gênero no jornalismo hegemônico brasileiro, uma vez que, historicamente, a voz masculina (ou, ao menos, a versão/visão masculina dos fatos) tem predominado nas narrativas da imprensa. Isso ajuda a compreender o porquê de muitas mulheres, ainda que alijadas de condições de igualdade no âmbito do trabalho ou na vida privada (e aqui citando apenas dois exemplos possíveis), optarem por se alinhar discursivamente a um discurso antifeminista.

Para verificar o poder de emudecimento condicionado por essa espiral do silêncio, basta rememorar brevemente o percurso histórico de construção da imagem da mulher na imprensa nacional. Isso porque é possível afirmar de forma inequívoca que o discurso Revista Pauta Geral-Estudos em Jornalismo, Ponta Grossa, vol. 6, n. 2, p. 3-19, Jul/Dez, 2019. 
REVISTA PAUTA GERAL

\section{ESTUDOS EM JORNALISMO}

10.5212/RevistaPautaGeral.v.6.i2.0001

misógino já faz parte do jornalismo hegemônico brasileiro desde a sua gênese, ainda no Brasil Império. É Rachel Soihet (2001) quem, no artigo Sutileza, Ironia e Zombaria: instrumentos no descrédito das lutas das mulheres pela emancipação, lembra que os primeiros movimentos ocorridos no século XIX foram ridicularizados pela imprensa, sendo a "utilização de discursos cômicos para desmoralizar a movimentação feminina quanto à obtenção de direitos [...] um instrumento de potencial inegável, com vista à reconstrução cotidiana dos mitos da inferioridade e domesticidade feminina" (SOIHET, 2001, n.p.).

Assim, o comportamento feminino reivindicador de uma participação mais plena na sociedade é visto como uma ameaça à ordem estabelecida, sob o signo dos interesses masculinos, na qual se teme a perda de seu predomínio nas relações de poder entre os gêneros. Inclusive, tais pressupostos adquiriam naquele momento legitimidade nos saberes hegemônicos da época (SOIHET, 2001, n.p.).

No mesmo caminho, em seus estudos sobre feminismo, poder e jornalismo, Mendéz (2007) observa que, ao longo da história, a "imprensa brasileira tem apresentado (de forma majoritária) um comportamento refratário aos ideais feministas, utilizando-se de diversos mecanismos discursivos para desqualificá-los" (MENDÉZ, 2007, p. 270). Contudo, a autora pontua que essa história não caminhou de forma linear, tampouco a partir de uma relação sempre vertical. Ao contrário, ao longo do século $\mathrm{XX}$, diferentes movimentos de aproximação e afastamento (entre feminismo e imprensa) marcaram a tentativa de incorporação de vozes femininas - e feministas - nos veículos hegemônicos, o que poderia condicionar, consequentemente, uma cisão na espiral do silêncio promovida pelo patriarcado.

Méndez (2007) destaca que durante os primeiros anos do século XX, na esteira da luta das mulheres por uma participação mais ativa e igual na sociedade, com a busca pela afirmação dos direitos civis, houve profunda resistência na imprensa, que se encarregou de propagar um discurso conservador [e masculino], que buscava reafirmar o "espaço doméstico" como ambiente natural da mulher:

Assim, nas primeiras décadas do século $\mathrm{XX}$, assiste-se aos esforços do feminismo liberal em afirmar os direitos civis das mulheres. Igualmente importante foi a contribuição das mulheres anarquistas, organizadas em associações e sindicatos, para a emancipação no mundo do trabalho e a afirmação dos direitos das trabalhadoras. Todavia, em que pesem essas ações de resistência, o poder do discurso misógino configurava um 


\section{REVISTA PAUTA GERAL}

\section{ESTUDOS EM JORNALISMO}

10.5212/RevistaPautaGeral.v.6.i2.0001

impasse para a ruptura dos papéis sociais historicamente construídos para as mulheres (MÉNDEZ, 2007, p. 273).

Durante as décadas de 1960, 1970 e 1980, contudo, ocorre uma mudança de perspectiva, com uma aproximação mais significativa do discurso feminista dos maiores jornais em circulação. Todavia, essa maior proximidade não garantiu uma mudança capaz de quebrar a espiral, seja porque o Brasil atravessava uma ditadura militar, com cerceamento da liberdade de expressão, seja porque essa relação dentre feminismo (enquanto pensamento e movimento social) e imprensa foi marcada por proximidades, afastamentos e resistências (MÉNDEZ, 2007).

Citando a pesquisa de Simone Schmidt, Méndez (2007) destaca que, enquanto o cenário de resistência à ditadura nos anos 1970 proporcionou a entrada do discurso feminista nas páginas dos grandes jornais, a partir dos anos 1980 houve "um recuo dessa simpatia ao feminismo pelos meios de comunicação” (MÉNDEZ, 2007, p. 275).

De acordo Schmidt (2000), haveria a interferência de um contexto histórico marcado nos anos 70 pela rebeldia, pela contestação aos governos militares, pelas revoluções sociais e a emergência de novos movimentos, que tornaria a intelectualidade brasileira mais simpática ao feminismo. Já nos anos 80 , a autora identifica um recuo de tais pensamentos e um agrupamento da intelectualidade em torno dos ideais neoliberais, o que justificaria uma tentativa de apagar o feminismo das páginas dos jornais (MÉNDEZ, 2007, p.276).

Entre idas e vindas na relação entre imprensa e feminismo, o fato é que a espiral do silêncio persiste, ainda que sob novos moldes com a chegada das redes sociais online. Isso porque, por mais que o avanço das pautas pela igualdade de gênero seja considerável (e aqui tomando pauta nos sentidos de luta social e de objeto de interesse da imprensa), com coberturas sobre assédio, condições iguais de trabalho, entre outros, o tipo de discurso que é produzido sobre temas sensíveis como o feminicídio, o aborto e a liberdade sexual na maior parte da mídia hegemônica não traz a profundidade e amplitude necessárias para quebrar o silenciamento que alimenta a sociedade patriarcal. Da mesma forma, as ações de grupos feministas dentro das redes sociais online, ainda que importantes, não conseguem uma dimensão que ofereça risco ao discurso dominante.

A naturalização da opressão se dá pela invisibilidade do debate a respeito. Nesse sentido, acredito que o feminismo nacional conseguiu 


\title{
REVISTA PAUTA GERAL
}

\section{ESTUDOS EM JORNALISMO}

\author{
10.5212/RevistaPautaGeral.v.6.i2.0001
}

\begin{abstract}
viabilizar por meio das disputas de redes sociais muitas de suas pautas. Contudo, não é possível deixar de fazer a autocrítica, que a aceitação se dá em pautas menos sensíveis. Falar de assédio e cantadas de ruas, por mais que compreendam um ponto muito relevante para a discussão sobre o direito de escolha sobre nossos corpos, é mais aceito e palatável que falar abertamente de aborto e lutar pela garantia desse direito de forma segura e legalizada (RIBEIRO, 2018, p. 105).
\end{abstract}

\section{Jornalismo de resistência e a literatura como caminho contra a espiral}

Karina Woitowicz (2012) destaca que "o movimento feminista desde cedo reconheceu o papel da mídia na produção de estereótipos de gênero" (WOITOWICZ, 2012, n.p.). De acordo com a autora, a percepção da continuidade dessa representação estereotipada da mulher a partir do olhar masculino foi fundamental para que se cultivasse a importância da criação ou reapropriação de espaços discursivos que podemos descrever como contra-hegemônicos, de resistência ou alternativos ${ }^{4}$.

É nesse sentido que as experiências dos grupos feministas e de mulheres no Brasil, durante a chamada "segunda onda" do feminismo, apontavam cada vez mais para a necessidade de criar um discurso próprio, capaz de fazer questionamentos e promover mudanças (WOITOWICZ, 2012, n.p).

Em seu estudo, Woitowicz (2012) lista importantes veículos alternativos que desempenharam esse papel de resistência no Brasil a partir dos anos 1970, como os jornais Brasil Mulher (1975-1979), Nós Mulheres (1976-1978) e Mulherio (1981-1987). A pesquisadora ainda apresenta experiências contemporâneas de organizações feministas no jornalismo impresso, desenvolvidas a partir dos anos 1990. Neste estudo, contudo, ainda que reconhecendo a importância ímpar dessas iniciativas e, também das ações de jornalismo desenvolvidas nas redes sociais online, opta-se por lançar o olhar para um formato cuja eficiência muitas vezes é colocada em xeque pelos próprios jornalistas: o jornalismo literário.

Gonçalves e Loureiro (2018) lembram da dificuldade que é falar do tracejado que divide literatura e jornalismo. Em parte, pode-se argumentar que isso ocorre pela impossibilidade de estabelecer fronteiras precisas entre as duas áreas no que se refere a

\footnotetext{
4 Woitowicz (2012) compreende a mídia alternativa a partir "do seu caráter contrahegemônico e dos parâmetros diferenciados dos meios tradicionais no que se refere às suas formas de produção, circulação e consumo, assumindo características próprias" (WOITOWICZ, 2012, n.p).
}

Revista Pauta Geral-Estudos em Jornalismo, Ponta Grossa, vol. 6, n. 2, p. 3-19, Jul/Dez, 2019. 


\section{REVISTA PAUTA GERAL}

\section{ESTUDOS EM JORNALISMO}

10.5212/RevistaPautaGeral.v.6.i2.0001

forma e conteúdo, uma vez que assim como a ficção busca elementos na realidade para a sua narrativa, o jornalismo (tido como relato da realidade) também cria fatos totalmente fantasiosos ao privilegiar determinadas fontes de discurso em detrimento do silêncio de outras. É o que ocorre na sociedade patriarcal com o discurso a mulher.

O objetivo deste trabalho não é aprofundar o debate sobre essa relação entre jornalismo e literatura, tarefa já realizada de forma mais detida e com mais vigor por pesquisadores em outros momentos (PINTO, 2008; GONÇALVES; LOUREIRO, 2018). Trata-se, efetivamente, de um esforço para colocar as produções realizadas pelo jornalismo literário (uma importante forma de representação social) como novos pontos de resistência que se somam àqueles apresentados por Woitowicz $(2008,2012)$ em diferentes estudos.

Mais precisamente, busca-se inserir a obra $A$ guerra não tem rosto de mulher, de Svetlana Aleksiévitch, como um importante marco de resistência, vez que dá voz às mulheres mais simples, quebrando (ao menos no espaço de sua narrativa) o ciclo perverso promovido pela espiral do silêncio fomentada pelo patriarcado.

\section{A guerra não tem rosto de mulher: uma análise hermenêutica}

A Segunda Guerra Mundial tem rosto de homem e voz masculina. Isso é: os discursos produzidos sobre a Segunda Guerra Mundial têm rosto de homem e voz masculina. E não é difícil perceber isso. Em quase todas as suas representações, seja no jornalismo, no cinema ou mesmo na literatura, as histórias sobre o conflito sempre relegaram às mulheres um papel secundário: de enfermeiras zelosas ou mães e esposas preocupadas. Por outro lado, as grandes estratégias, as batalhas épicas, o sofrimento e as provações no front, as vitórias e o retorno triunfal ao lar sempre foram reservados aos homens, apontados como protagonistas e donos da história.

Destarte, com o passar das décadas, comprovou-se o poder do dito popular e uma mentira contada incansavelmente (ou um conjunto delas propagado em múltiplos espaços de representação social) acabou ganhando traços de "verdade", formando na memória coletiva uma imagem que não condiz com a realidade do evento.

Tudo o que sabemos da guerra conhecemos por uma "voz masculina". Somos todos prisioneiros de representações e sensações "masculinas" da guerra. Das palavras "masculinas". Já as mulheres estão caladas. Ninguém, além de mim, fazia perguntas para minha avó. Para minha 


\section{REVISTA PAUTA GERAL}

\section{ESTUDOS EM JORNALISMO}

10.5212/RevistaPautaGeral.v.6.i2.0001

mãe. Até as que estiveram no front estão caladas. Se de repente começam a lembrar, contam não a guerra "feminina", mas a "masculina". Seguem o cânone (ALEKSIÉVITCH, 2016, p.12).

Quem desvenda essa distorção masculina da história é a escritora bielorrussa Svetlana Aleksiévitch que, com seu jornalismo literário, reuniu os relatos de centenas de mulheres que participaram da Segunda Guerra Mundial ${ }^{5}$ como combatentes do Exército Vermelho, dando origem ao livro A guerra não tem rosto de mulher.

Em traços gerais, o jornalismo literário de Svetlana se diferencia de outras abordagens do gênero (como aquelas desenvolvidas por autores do New Journalism) no que se refere à incorporação de elementos de ficção na obra. Isso porque a principal característica do estilo não surge pelo enriquecimento dos cenários e/ou enredo a partir de composições do imaginário da autora, mas da subjetividade que emerge dos diferentes tempos de narrativa que marcam todo o processo produtivo durante as entrevistas $\mathrm{e}$ coletas dos relatos: as memórias afetivas das ex-combatentes, a pressão do discurso hegemônico que confunde as memórias das entrevistadas três décadas após a guerra, o afeto dos encontros entre a própria autora e as mulheres, a presença ou não de homens nos ambientes durante as conversas, entre outros.

Vozes... Dezenas de vozes... Elas desabaram sobre mim, revelando uma verdade insólita, e ela, essa verdade, já não cabia naquela estreita fórmula que eu conhecia desde a infância: nós vencemos. Uma reação química instantânea aconteceu: a retórica se diluiu no tecido vivo dos destinos humanos; ela se revelou a substância com menor tempo de vida. Destino é quando há algo mais por trás das palavras (ALEKSIÉVITCH, 2016, p. 61).

Em análise anterior da obra, tomando os estudos de Walter Benjamin sobre o narrador e a experiência como prisma de observação, Gonçalves e Loureiro (2018) destacam que uma característica da obra de Aleksiévitch é sua organização extremamente polifônica e fragmentada. É a partir dessa reunião de vozes que estavam silenciadas que a jornalista consegue construir um "exemplo vivo da experiência coletiva na narrativa" (GONÇALVES; LOUREIRO, 2018, p. 209). Porém, como indicado na introdução deste trabalho, o objetivo aqui não foi retomar a discussão sobre o papel do

5 Estima-se que um milhão de mulheres integraram o Exército Vermelho durante a Segunda Guerra, ocupando postos de sapadoras, comandantes, enfermeiras, batedoras, partisans, padeiras, lavadeiras, médicas, pilotas, franco-atiradoras, fuzileiras, carteiras, entre outras funções (GONÇALVES; LOUREIRO, 2018).

Revista Pauta Geral-Estudos em Jornalismo, Ponta Grossa, vol. 6, n. 2, p. 3-19, Jul/Dez, 2019. 


\section{REVISTA PAUTA GERAL}

\section{ESTUDOS EM JORNALISMO}

10.5212/RevistaPautaGeral.v.6.i2.0001

narrador na obra, mas, a partir de uma análise hermenêutica, buscar quais características presentes no jornalismo literário de Aleksiévitch contribuem para a luta contra a espiral do silêncio constituída pelo patriarcado na antiga URSS ${ }^{6}$. Assim, pautando-se na teoria de Noelle-Neuman (1995) durante o processo teórico-reflexivo de leituras e releituras do livro, chegou-se a três contribuições principais que podem auxiliar na propagação das vozes femininas e feministas na contemporaneidade, sendo elas: i) a valorização das histórias "menores" e das pessoas mais simples diante de toda a "pseudo-grandiosidade" dos relatos dos homens; ii) também a partir das pessoas mais simples, a elucidação do processo de apuração e dos choques discursivos como parte integrante da própria história; e iii) a convergência de elementos factuais nos fragmentos que colocam em xeque a versão hegemônica a partir de uma reunião de vozes que estavam silenciadas.

Valorização das histórias "menores". Uma das principais contribuições para romper a espiral do silêncio trazidas por Aleksiévitch é a apropriação das histórias tidas como "menores" - as "ninharias de mulheres" (ALEKSIÉVITCH, 2016, p. 22) -, sobretudo aquelas contadas pelas ex-combatentes mais simples que, na visão da autora, estariam menos influenciadas pelo discurso hegemônico masculino, se aproximando, portanto, com mais precisão da realidade. Ao trazer elementos tidos como corriqueiros da vida e do cotidiano no front, como a dificuldade das mulheres em conseguirem fardas e botas adequadas ao seu tamanho, o sofrimento pelo abatimento de um animal ou por ter que raspar o cabelo e as dificuldades de se lavar um casaco com sangue congelado em meio à neve, a jornalista liberta as vozes sobre uma parte da guerra desconsiderada pelo discurso hegemônico, que opta por esquecer que "mesmo na guerra mais da metade da vida é composta de afazeres banais" (ALÉKSIÉVITCH, 2016, p. 210).

A história relatada por uma testemunha ou por um participante que ninguém notou. Sim, é isso que me interessa, é isso que eu gostaria de transformar em literatura. Mas as pessoas que contavam não eram

\footnotetext{
6 Vale ressaltar que o fato de o livro ter sido construído a partir de relatos (hegemônicos e contra-hegemônicos) na Sociedade Soviética não representa um empecilho para a utilização do modelo de produção de Aleksiévitch como forma de resistência ao neoliberalismo que assola as sociedades contemporâneas. Ao contrário, a força da obra reside justamente na contribuição que ela traz ao desvelar que a sociedade patriarcal pode se perpetuar em diferentes modelos de organização econômica e social, a persistirem o silenciamento e a imposição das vozes masculinas sobre as femininas. Em outros termos, ela mostra que uma revolução socialista efetiva precisaria ser, também, uma revolução feminista.
}

Revista Pauta Geral-Estudos em Jornalismo, Ponta Grossa, vol. 6, n. 2, p. 3-19, Jul/Dez, 2019. 


\title{
REVISTA PAUTA GERAL
}

\section{ESTUDOS EM JORNALISMO}

10.5212/RevistaPautaGeral.v.6.i2.0001

\begin{abstract}
apenas testemunhas, menos que tudo testemunhas: eram atores e criadores. É impossível chegar muito perto da realidade, cara a cara. Entre a realidade e nós existem os nossos sentimentos. Entendo que estou lidando com versões, cada um tem a sua, e delas, do volume e do cruzamento delas, nasce a imagem do tempo e das pessoas que vivem nele. Eu não gostaria que, a respeito do meu livro, dissessem: os personagens dela são reais e nada mais. Que dissessem: é a história. Apenas a história (ALEKSIÉVITCH, 2016a, p. 18).
\end{abstract}

É claro que as histórias do sofrimento da guerra contadas ao longo das décadas pelo ponto de vista masculino também estão presentes, com incontáveis mortes, cirurgias e amputações em meio ao fogo cruzado no front, emboscadas nas estradas, atentados com as minas terrestres, entre outros. A diferença é que as mulheres aqui também são protagonistas dessas narrativas (e não apenas enfermeiras zelosas). Assim como são protagonistas das tarefas cotidianas, atuando como "lavadeiras, cozinheiras, mecânicas, carteiras" (ALEKSIÉVITCH, 2016, p. 210). Porém, como diferenciar as faces da guerra quando todas elas trouxeram sofrimento e silêncio às mulheres? Como optar por contar uma história em detrimento da outra em meio a tantas vozes emudecidas? Como escolher para qual pauta permitir a voz? É essa a primeira lição/contribuição da autora para o jornalismo de resistência à espiral do silêncio aqui proposto: não diferenciar o sofrimento a partir dos critérios objetivos do relato masculino, mas dar a todas as vítimas de barbáries direito de voz. "Como chamar o pequeno de pequeno, e o grande de grande, quando um e outro são igualmente infinitos? Já faz tempo que não os diferencio" (ALEKSIÉVITCH, 2016, p.190).

Choques discursivos como parte da história. Outra contribuição da autora está na incorporação do discurso hegemônico como contraponto à sua própria narrativa. Isso é, ao invés de optar por contar apenas a história das mulheres, cedendo espaço exclusivo às vozes silenciadas, Aleksiévitch realiza um verdadeiro movimento dialógico, externando ao longo do texto os choques desses discursos femininos com a "versão oficial" propagada pelos homens e, também pelas mídias hegemônicas. Essa estratégia permite ao leitor desvendar por si só os sofismos que marcam as narrativas masculinas da guerra, muitas delas já incorporadas no repertório das pessoas mais cultas através da acumulação, consonância e ubiquidade (mecanismos que, conforme mencionado, levam à formação da espiral do silêncio). 
REVISTA PAUTA GERAL

\title{
ESTUDOS EM JORNALISMO
}

10.5212/RevistaPautaGeral.v.6.i2.0001

\begin{abstract}
Os mais sinceros, estou convencida, são as pessoas simples enfermeiras, cozinheiras, lavadeiras... Elas - como definir com mais precisão? - tiram as palavras de si mesmas, e não dos jornais ou dos livros que leram, não do que é alheio. Apenas dos próprios sofrimentos e emoções. Os sentimentos e a linguagem das pessoas cultas, por mais estranho que pareça, estão mais sujeitos a ser reelaborados pelo tempo. Pela codificação geral. Contaminados pelo conhecimento indireto. Pelos mitos (ALEKSIÉVITCH, 2016, p.14-15).
\end{abstract}

A estratégia da autora é importante uma vez que dentro de cada lar visitado por ela na URSS existiam pelo menos "duas guerras". Uma exposta em quadros e medalhas nas paredes, motivo de relatos entusiasmados, e outra, silenciada frente o discurso dominante. E é estabelecendo esse choque de discursos que a autora desvela a razão principal da espiral do silêncio formada pelas narrativas do patriarcado: a guerra não era coisa de mulher, portanto, melhor seria - na visão imposta pelos homens - esquecer ou amenizar a participação feminina:

Para quem eu ia dizer que estava ferida, lesionada? Você experimenta dizer, depois quem vai lhe dar um emprego, quem vai casar com você? [...] No começo nós escondíamos, não usávamos nem as medalhas. Os homens usavam, as mulheres não. Os homens eram vencedores, heróis, noivos, a guerra era deles; já para nós, olhavam com outros olhos. Era completamente diferente... Vou Ihe dizer, tomaram a vitória de nós. $\mathrm{Na}$ surdina, trocaram pela felicidade feminina comum (ALEKSIÉVITCH, 2016, p. 156).

Nós, as garotas do front, já tínhamos aguentado o suficiente. E depois da guerra ainda tivemos mais uma guerra. Terrível também. Os homens de alguma forma nos largaram (ALEKSIÉVITCH, 2016, p. 388).

Convergência de elementos. Outro ponto forte da narrativa construída pela autora está na convergência de elementos factuais em diferentes relatos. Assim, em discursos de ex-combatentes que jamais se conheceram ou se encontraram surgem elementos narrativos comuns, que endossam a força de verdade do discurso. Nessa multiplicação de vozes femininas surgem novas faces de barbárie do horror da guerra, apresentando-se desde relatos sobre a ausência de menstruação e o embranquecimento precoce dos cabelos durante os anos no front; até os casos de violência contra as mulheres alemãs, com os estupros coletivos cometidos nas vilas ocupadas.

Eu me lembro... Claro, lembro de uma alemã estuprada. Ela estava deitada nua, com uma granada enfiada no meio das pernas... [...] Cinco jovens alemãs vieram falar com nosso comandante. Elas choravam. $\mathrm{O}$

Revista Pauta Geral-Estudos em Jornalismo, Ponta Grossa, vol. 6, n. 2, p. 3-19, Jul/Dez, 2019. 


\title{
REVISTA PAUTA GERAL
}

\section{ESTUDOS EM JORNALISMO}

10.5212/RevistaPautaGeral.v.6.i2.0001

\begin{abstract}
ginecologista examinou: elas tinham feridas lá. Feridas rasgadas. Todas as calcinhas ensanguentadas... Tinham sido estupradas por toda a noite. Os soldados faziam fila... (ALEKSIÉVITCH, 2016, p. 364-365).
\end{abstract}

Nuances do horror de uma guerra que - como todas as guerras - não teve vencedores, mas que não podia ser contada a partir de um olhar feminino, afinal a denúncia de estupros, da humilhação sofrida pelas mulheres que participaram do front e de suas preocupações com "pormenores" poderiam "atrapalhar" o relato hegemônico masculino dos "vencedores". Nessa toada, para não se dar qualquer chance de que alguma voz se levantasse afirmando o contrário, tratou-se de produzir pelas vias da indústria da cultura - não apenas na URSS, mas entre todos os Aliados - um relato épico (e masculino) da batalha, silenciando as vozes femininas.

Sabendo que o relato isolado de uma mulher faria pouca diferença frente todo o desserviço misógino já feito, Aleksiévitch tratou de reunir centenas delas, sendo a construção de um discurso coletivo contra-hegemônico sua grande contribuição para estabelecer uma resistência ou mesmo quebrar de alguma forma espiral do silêncio, ainda que ao custo de longos anos. E isso, embora pareça pouco perante todo aparato dos media, já é uma conquista significativa para contestação da sociedade patriarcal, afinal "[...] é terrível lembrar, mas é mais terrível ainda não lembrar" (ALEKSIÉVITCH, 2016, p. 159).

\section{Considerações finais}

Buscou-se, neste artigo, apresentar a obra de Svetlana Aleksiévitch como um possível ponto de resistência para as vozes femininas à espiral do silêncio produzida pelas mídias hegemônicas a favor do patriarcado. Obviamente, não se pretende com a análise hermenêutica aqui realizada (tampouco com as breves revisões bibliográficas desenvolvidas) encerrar os debates neste artigo em torno de uma defesa definitiva do jornalismo literário como a "melhor" estratégia para a luta feminista diante das construções simbólicas de gênero. A ideia, ao contrário, é apontá-lo como uma possibilidade entre tantas outras, melhor apresentadas nos estudos de Woitowicz (2008, 2012). Nesse caminho valem mais, portanto, as estratégias construídas por Aleksiévitch (como os choques discursivos e a convergência de elementos factuais a partir das múltiplas vozes silenciadas) do que o próprio gênero jornalístico/literário em questão, vez que esses elementos, quando incorporados ao jogo discursivo, podem ser utilizados por formatos 2019. 


\section{REVISTA PAUTA GERAL}

\section{ESTUDOS EM JORNALISMO}

10.5212/RevistaPautaGeral.v.6.i2.0001

mais dinâmicos e céleres de representação social, como as próprias redes sociais online, fornecendo ao feminismo - enquanto pensamento e movimento social - novas possibilidades de enfrentamento à representação masculina do mundo.

\section{Referências}

ACUÑA, M. E. Conceptos fundamentales: posición occidental del sujeto teórico, tensiones sobre la idea biologicista de la mujer. Material do curso Introducción a las teorías feministas. Santiago: Universidad de Chile, 2019.

ALEXANDRE, J. C. Uma genealogia da espiral do silêncio: a expressão da opinião sobre as praxes acadêmicas. Covilhã (Portugal): Editora LabCom.IFP, 2018.

ALEKSIÉVITCH, S. A guerra não tem rosto de mulher. São Paulo: Companhia das Letras, 2016.

BEAUVOIR, S. d. O segundo sexo - Volume 1: fatos e mitos. São Paulo: Difusão Europeia do Livro, 1970.

GONÇALVES, E.; LOUREIRO, R. Limites entre jornalismo e literatura em "A guerra não tem rosto de mulher", de Svetlana Aleksiévitch: uma análise do narrador a partir do conceito benjaminiano de Erfahrung. Via Atlântica, n. 34, p. 193-210, 2018.

MÉNDEZ, N. Feminismo, imprensa e poder no Brasil contemporâneo. MÉTIS: história \& cultura, v. 6, n. 12, p. 269-288, jul./dez. 2007.

NOELLE-NEUMANN, E. La espiral del silencio: opinión pública - nuestra piel social. Barcelona: Paidós, 1995.

PENA, F. Teorias do jornalismo. 3. ${ }^{a}$ ed. São Paulo: Contexto, 2018.

PINTO, M. d. O. O jornalismo como gênero literário. Contexto: Revista da Faculdade de Filosofia e Ciências Sociais da UERN, v. 3, n. 3, p. 59-72, 2008.

RIBEIRO, S. Feminismo: um caminho longo à frente. In: GALLEGO, E. S. (org.) O ódio como política. São Paulo: Boitempo, 2018.

SILVA, D. S.; AZEVEDO, N. P. G.; FILGUEIRAS, A. A. Bela, recatada e do lar: uma análise discursiva das posições-sujeito da mulher na revista Veja. Entretextos, v. 17, n. 1, p. 209229,2017.

SOIHET, R. Sutileza, ironia e zombaria: instrumentos no descrédito das lutas das mulheres pela emancipação. In: MURARO, R. M. (org). Mulher, gênero e sociedade. Rio de Janeiro: Relume Dumará, 2001. 


\section{REVISTA PAUTA GERAL}

\section{ESTUDOS EM JORNALISMO}

10.5212/RevistaPautaGeral.v.6.i2.0001

WOITOWICZ, K. J. Imprensa feminista no contexto das lutas das mulheres: ativismo midiático, cidadania e novas formas de resistência. Revista Ação Midiática, v. 2, n. 1 , 2012.

WOITOWICZ, K. J. Páginas que resistem - A imprensa feminista na luta pelos direitos das mulheres no Brasil. In: Anais dos VI Congresso Nacional de História da Mídia, 2008, Niterói/RJ.

Recebido em: 15/10/2019

Aprovado em: 11/11/2019 